\title{
Studies on Olfactory Thresholds in Normal Man and in Patients with Adrenal Cortical Insufficiency: The Role of Adrenal Cortical Steroids and of Serum Sodium Concentration *
}

\author{
Robert I. Henkin † and Frederic C. Bartter \\ (From the Clinical Endocrinology Branch, National Heart Institute, National Institutes of \\ Health, Bethesda, Md.)
}

Patients with adrenal cortical insufficiency exhibit a greater sensitivity than normal for each of the four modalities of taste (1). Treatment with deoxycorticosterone acetate does not alter these lowered thresholds, whereas treatment with carbohydrate-active steroids returns them to normal (1). In a variety of acute and chronic debilitating diseases, a number of them exhibiting major abnormalities of water and electrolyte metabolism, taste thresholds are comparable to those observed in healthy subjects (2). In cystic fibrosis of the pancreas taste thresholds for all four modalities are below normal, but they do not change after treatment with steroids (3).

The present study was designed to examine olfactory thresholds in patients with adrenal insufficiency. They were found to be abnormal, and the effects of sodium-retaining and of carbohydrateactive steroids were measured.

\section{Methods}

The subjects of this study were 41 normal volunteers, aged 6 to $59 ; 56$ patients with various acute and chronic diseases, aged 5 to $61 ; 2$ patients with anterior pituitary insufficiency, aged 21 and 36 ; and 9 patients with adrenal cortical insufficiency, aged 18 to 65 . Taste thresholds were previously reported for the two patients with anterior pituitary insufficiency and four of the nine patients with adrenal cortical insufficiency (1). All patients with adrenal cortical insufficiency had clinical features of this disease, urinary 17-hydroxycorticosteroids below $2 \mathrm{mg}$ per 24 hours that did not increase with ACTH (40 U given intravenously over 8 hours daily for 5 days). Both patients with anterior pituitary insufficiency had hypothyroidism and hypogonadism; uri-

* Submitted for publication February 15, 1966; accepted July 12, 1966.

$\dagger$ Address requests for reprints to Dr. Robert I. Henkin, Clinical Endocrinology Branch, National Heart Institute, Bethesda, Md. 20014. nary 17-hydroxycorticosteroids were 1.1 and $2.2 \mathrm{mg}$ per day in J.M. and S.P., respectively, rising to 27.0 and $10.9 \mathrm{mg}$ per day, respectively, with ACTH (40 U over 8 hours). All patients remained on an air-conditioned metabolic ward and ate a normal diet, which was well tolerated even when they were not receiving treatment. Sodium intake was 100 to $200 \mathrm{mEq}$ per day. Body weight, determined with metabolic scales daily on arising, was used to provide a gross estimate of change in the volume of body fluids. The patients were studied under each of four conditions : $a$ ) untreated for 4 or more days, b) treated with deoxycorticosterone acetate (DOC), 20 mg per day for 2 to 7 days, $c$ ) treated with prednisolone $\left(\Delta^{1}-\mathrm{F}\right), 20 \mathrm{mg}$ per day for 2 to 5 days, and $d$ ) treated with 9 - $\alpha$-fluorohydrocortisone ( 0.05 to $0.10 \mathrm{mg}$ daily) and with maintenance doses of prednisolone (5.0 to 7.5 $\mathrm{mg}$ daily) or cortisone acetate $(37.5 \mathrm{mg}$ daily) or dexamethasone ( $0.5 \mathrm{mg}$ daily).

Smell was evaluated by measuring the detection threshold, defined as the lowest concentration of test solution that could be consistently distinguished as different from its carrier solution, either glass-distilled water or mineral oil. For pyridine, thiophene, and nitrobenzene, we also measured a recognition threshold, the lowest concentration of test solution that could be consistently recognized. Thresholds were measured by one observer in the early morning in the normal subjects and in the morning, evening, or both in the patients with adrenal insufficiency. Occasional retesting of the patients by another observer gave comparable results on each occasion. At the time of testing, the patients had not smoked or eaten for at least 1 hour. The solutions of test substance or carrier were administered in narrownecked $60-\mathrm{ml}$ glass or $30-\mathrm{ml}$ plastic bottles, kept at room temperature (approximately $22 \mathrm{C}$ ), and held 2 to $5 \mathrm{~cm}$ beneath the nose. We instructed the subjects to inspire at each presentation of the stimulus. This was demonstrated by the experimenter and repeated by the subject until a consistent pattern of inspiration through the nose with the mouth closed was achieved. This inspiratory pattern allows the intake of approximately $60 \mathrm{ml}$ of vapor at each inhalation (4).

Each test solution was presented to the patients together with two solutions of carrier. The patients were requested to state which of the three solutions smelled 
TABLE I

Detection and recognition thresholds for olfaction in normal subjects

\begin{tabular}{|c|c|c|c|c|}
\hline \multirow[b]{2}{*}{ Substance } & \multicolumn{2}{|c|}{ Detection } & \multicolumn{2}{|c|}{ Recognition } \\
\hline & $\begin{array}{c}\text { Median } \\
\text { detection } \\
\text { threshold }\end{array}$ & Range & $\begin{array}{c}\text { Median } \\
\text { recogni- } \\
\text { tion } \\
\text { threshold }\end{array}$ & Range \\
\hline & \multicolumn{2}{|c|}{ mmoles $/ L$} & \multicolumn{2}{|c|}{ mmoles $/ L$} \\
\hline $\mathrm{NaCl}$ & $>300$ & $150->300$ & & \\
\hline $\mathrm{KCl}$ & $>300$ & $150->300$ & & \\
\hline $\mathrm{NaHCO}_{2}$ & $>300$ & $150->300$ & & \\
\hline Sucrose & $>300$ & $150->300$ & & \\
\hline Urea & $>300$ & $120->300$ & & \\
\hline $\mathrm{HCl}$ & $>300$ & $150->300$ & . & \\
\hline Pyridine in $\mathrm{H}_{2} \mathrm{O}$ & $10^{-6}$ & $10^{-2}-10^{-6}$ & $10^{-1}$ & $10^{-1}-10^{-2}$ \\
\hline Thiophene in $\mathrm{H}_{2} \mathrm{O}$ & $10^{-3}$ & $10^{-1}-10^{-5}$ & $10^{\circ}$ & $10-10^{-1}$ \\
\hline Thiophene in oil & $10^{-8}$ & $10^{-2}-10^{-5}$ & $10^{-1}$ & $10^{-1}-10^{-2}$ \\
\hline Nitrobenzene in oil & $10^{-4}$ & $10^{-2}-10^{-5}$ & $10^{-1}$ & $10^{-1-10^{-2}}$ \\
\hline
\end{tabular}

different from the other two. The test solutions ranged from pure or undiluted to dilute solutions that could not be distinguished from water or mineral oil by normal subjects. As the concentration of test substance in successive tests was lowered, a transition point was found, where responses changed from consistently correct to random ones. Retests were made at and around the transition point. Threshold was defined as the lowest concentration of test substance to which the subject gave two successive correct responses while giving two consecutive incorrect responses at the next lower concentration. Thirteen different concentrations of test solution were each presented at least twice, and the order of presentation was varied. The probability that a threshold is determined by chance under these conditions is 1 in 2,500.1 In this manner, olfactory thresholds were determined for representatives of each of the four basic taste modalities, including vapors that are usually considered nonodorous. These included sodium chloride $(\mathrm{NaCl})$, potassium chloride $(\mathrm{KCl})$, sodium bicarbonate $\left(\mathrm{NaHCO}_{3}\right)$, sucrose, urea, and hydrochloric acid (HCL). Olfactory thresholds were also determined for odorous vapors. These included pyridine diluted in water, thiophene diluted in both water and in mineral oil, and nitrobenzene diluted in mineral oil.

\section{Results}

\section{Olfactory thresholds in normal subjects}

Approximately $75 \%$ of the subjects could not detect any difference between two samples of water and one containing a concentration as great as 300 mmoles per $\mathrm{L}$ of $\mathrm{NaCl}, \mathrm{KCl}, \mathrm{NaHCO}_{3}$, sucrose, urea, or $\mathrm{HCl}$. The remainder of the normal sub-

1 Statistical analysis of the method required that a model of the experimental design be made. Based on this model all possible combinations of patient response were evaluated. The probability determination given above is the result of these calculations. jects could detect the above solutes in concentrations as great as 300 mmoles per L, although they could not detect them when the concentration of test solution was less than 120 mmoles per L ( Table I). All normal subjects could easily detect test solutions of pyridine, thiophene, or nitrobenzene as different from water or mineral oil (Table I). Normal detection thresholds for these substances were as follows: for pyridine in water and thiophene in oil, $10^{-5}$ mmole per L; for nitrobenzene in oil, $10^{-4}$ mmole per $\mathrm{L}$; and for thiophene in water, $10^{-3}$ mmole per L.

Recognition thresholds for $\mathrm{NaCl}, \mathrm{KCl}, \mathrm{Na}-$ $\mathrm{HCO}_{3}$, sucrose, urea, and $\mathrm{HCl}$ could not be obtained by olfactory cues alone. Those subjects who could detect differences stated that they were aware of some difference between the solutions and water, but they could not consistently say how they were aware of these differences, and they could not attach any consistent quality to the solutions. For the other substances, recognition thresholds for pyridine in water and thiophene and nitrobenzene in mineral oil were the same, 0.1 mmole per L; the recognition threshold for thiophene in water was 1.0 mmole per $\mathrm{L}$. These recognition thresholds are 1,000 to 10,000 times greater than the corresponding detection thresholds.

Similar detection and recognition thresholds for these same substances were measured in 56 patients with various acute and chronic diseases. Thresholds were within the normal range in these patients in spite of serum sodium concentrations ranging from 112 to $170 \mathrm{mEq}$ per L.

\section{Olfactory thresholds in adrenal insufficiency}

Without treatment. The detection threshold for each substance in each patient with adrenal insufficiency, off treatment, is presented in Table II. The medians of the detection thresholds for the patients are as follows: for $\mathrm{NaCl}, \mathrm{KCl}, \mathrm{Na}$ $\mathrm{HCO}_{3}$, and sucrose, $10^{-4}$ mmole per L; for urea, $8 \times 10^{-4}$ mmole per $\mathrm{L}$; and for $\mathrm{HCl}, 6 \times 10^{-5}$ mmole per L (Table II). Because of the great dilution of these substances and the errors attendant on the threshold measurements the median detection thresholds for all these substances can, for practical purposes, be considered the same. All patients with adrenal insufficiency showed a markedly increased ability to detect all substances 
TABLE II

Detection thresholds for olfaction in adrenal insufficiency

\begin{tabular}{|c|c|c|c|c|c|c|c|c|c|}
\hline \multirow[b]{2}{*}{ Patient } & \multirow[b]{2}{*}{ Weight } & \multirow{2}{*}{$\underset{\mathrm{Na}}{\text { Serum }}$} & \multirow{2}{*}{$\underset{\mathbf{K}}{\text { Serum }}$} & \multicolumn{6}{|c|}{ Detection threshold } \\
\hline & & & & $\mathrm{NaCl}$ & $\mathrm{KCl}$ & $\mathrm{NaHCO}$, & Sucrose & Urea & $\mathrm{HCl}$ \\
\hline & kg & \multicolumn{2}{|c|}{$m E q / L$} & \multicolumn{6}{|c|}{ mmole $/ L$} \\
\hline \multicolumn{4}{|c|}{ A. Addison's disease } & & & & & & \\
\hline G.B. & 47.16 & 144 & 5.2 & $10^{-4}$ & $10^{-4}$ & $10^{-4}$ & $10^{-4}$ & $8 \times 10^{-4}$ & $6 \times 10^{-5}$ \\
\hline J.D. & 68.87 & 137 & 5.4 & $10^{-3}$ & $10^{-3}$ & $10^{-3}$ & $10^{-3}$ & $8 \times 10^{-3}$ & $6 \times 10^{-5}$ \\
\hline H.T. & 77.07 & 138 & 4.1 & $10^{-4}$ & $10^{-4}$ & $10^{-4}$ & $10^{-4}$ & $8 \times 10^{-4}$ & $6 \times 10^{-5}$ \\
\hline R.P. & 62.97 & 130 & 3.8 & $10^{-5}$ & & & $10^{-5}$ & $8 \times 10^{-5}$ & $6 \times 10^{-5}$ \\
\hline G.T. & 51.68 & 140 & 4.6 & $10^{-5}$ & & & $10^{-5}$ & $8 \times 10^{-4}$ & $6 \times 10^{-6}$ \\
\hline S.S. & 46.98 & 140 & 4.5 & $10^{-5}$ & $10^{-5}$ & $10^{-4}$ & $10^{-4}$ & $8 \times 10^{-3}$ & $6 \times 10^{-6}$ \\
\hline R.H. & 63.65 & 134 & 5.9 & $10^{-5}$ & $10^{-5}$ & $10^{-5}$ & $10^{-5}$ & $8 \times 10^{-5}$ & $6 \times 10^{-6}$ \\
\hline P.E. & 46.40 & 136 & 4.3 & $10^{-5}$ & $10^{-5}$ & $10^{-4}$ & $10^{-5}$ & $8 \times 10^{-5}$ & $6 \times 10^{-6}$ \\
\hline P.K. & 46.05 & 137 & 5.1 & $10^{-4}$ & $10^{-4}$ & $10^{-4}$ & $10^{-5}$ & $8 \times 10^{-5}$ & $6 \times 10^{-6}$ \\
\hline \multicolumn{10}{|c|}{ B. Panhypopituitarism } \\
\hline S.P. & 32.19 & & & $10^{-4}$ & $10^{-4}$ & $10^{-4}$ & $10^{-4}$ & $8 \times 10^{-4}$ & $6 \times 10^{-5}$ \\
\hline & 72.10 & 147 & 5.1 & $10^{-3}$ & $10^{-2}$ & $10^{-2}$ & $10^{-3}$ & $8 \times 10^{-3}$ & $6 \times 90^{-3}$ \\
\hline Median & & & & $10^{-4}$ & $10^{-4}$ & $10^{-4}$ & $10^{-4}$ & $8 \times 10^{-4}$ & $6 \times 10^{-5}$ \\
\hline Range & & & & $10^{-3}-10^{-5}$ & $10^{-2}-10^{-5}$ & $10^{-2}-10^{-5}$ & $10^{-3}-10^{-5}$ & $10^{-3}-10^{-5}$ & $10^{-3}-10^{-6}$ \\
\hline
\end{tabular}

tested. They could detect concentrations of solute $10^{-3}$ to $10^{-8}$ times the minimal concentrations detected by the most sensitive normal subjects. For no substance did the range of thresholds in the patients with adrenal insufficiency overlap that in the normal subjects.

This increased olfactory sensitivity was found with odorous substances as well as for those usually considered nonodorous. Olfactory thresholds were measured in four patients with pyridine, thiophene, and nitrobenzene. The patients could detect the test solutions in concentrations $10^{-3}$ to $10^{-8}$ times the minimal concentrations detected by the most sensitive of the normal subjects (Figure 1). Again, the range of thresholds observed in patients with adrenal cortical insufficiency did not overlap the range observed for these substances in normal subjects (Figure 1).

Treated with Na-retaining steroids. The detection threshold for each substance in each patient with adrenal insufficiency treated with DOC alone is presented in Table III. The median detection thresholds for the patients are as follows: for $\mathrm{NaCl}, \mathrm{NaHCO}_{3}, \mathrm{KCl}$, and sucrose, $10^{-4}$ mmole per L; for urea, $8 \times 10^{-4}$ mmole per L; and for $\mathrm{HCl}, 6 \times 10^{-5}$ mmole per L (Table III). These median detection thresholds are exactly the same as those observed during the periods without treatment (Table II) despite a return of serum sodium and potassium concentrations toward normal and increases in body weight (Table III). Similar results were obtained in the four patients in whom thresholds for pyridine, thiophene, and nitrobenzene were studied (Table V).

Treated with carbohydrate-active steroids. The detection threshold for each substance in each patient with adrenal insufficiency treated with pred-

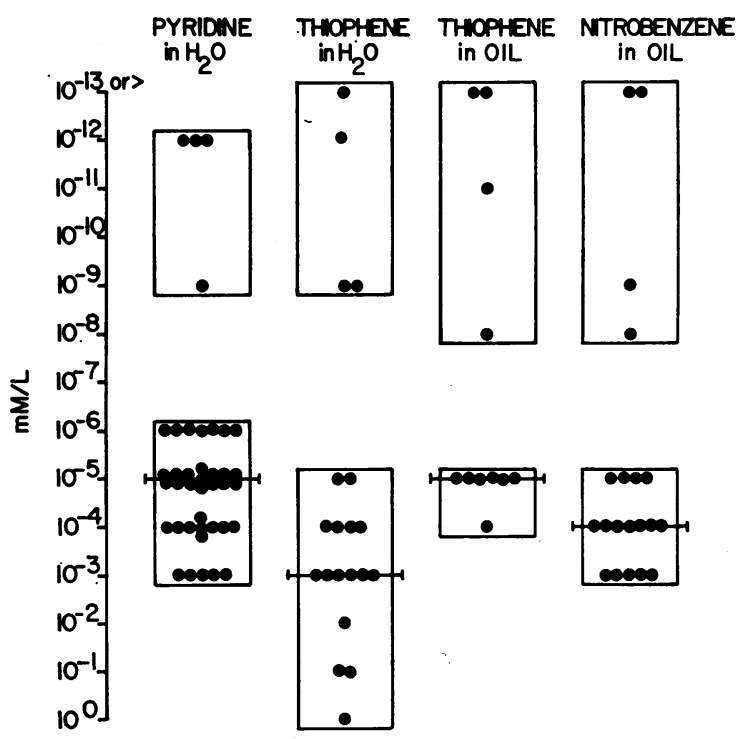

Fig. 1. The median and Range of the Detection THRESHOLD FOR PYRIDINE IN WATER, THIOPHENE IN WATER, THIOPHENE IN OIL, AND NITROBENZENE IN OIL IN ADRENAL INSUFFICIENCY (ADDISON'S DISEASE AND PANHYPOPITUITARISM) AND IN NORMAL VOLUNTEERS. The dots represent detection thresholds for the individual subjects, the height of the box represents the range, and the lines through the boxes represent the median detection threshold. There is no overlap between the thresholds of the patients and those of the normal volunteers. 
TABLE III

Detection thresholds for olfaction in adrenal insufficiency treated with deoxycorticosterone acetate

\begin{tabular}{|c|c|c|c|c|c|c|c|c|c|}
\hline \multirow[b]{2}{*}{ Patient } & \multirow[b]{2}{*}{ Weight } & \multirow{2}{*}{$\begin{array}{c}\text { Serum } \\
\mathrm{Na}\end{array}$} & \multirow{2}{*}{$\underset{K}{\text { Serum }}$} & \multicolumn{6}{|c|}{ Detection threshold } \\
\hline & & & & $\mathrm{NaCl}$ & $\mathrm{KCl}$ & $\mathrm{NaHCO}_{3}$ & Sucrose & Urea & $\mathrm{HCl}$ \\
\hline & $k g$ & \multicolumn{2}{|c|}{$m E q / L$} & \multicolumn{6}{|c|}{ mmole $/ L$} \\
\hline \multirow{2}{*}{\multicolumn{4}{|c|}{ A. Addison's disease }} & & & & & & \\
\hline G.B. & 48.55 & 145 & & $10^{-4}$ & $10^{-4}$ & $10^{-4}$ & $10^{-4}$ & $8 \times 10^{-4}$ & $6 \times 10^{-5}$ \\
\hline J.D. & 71.92 & 142 & 3.3 & $10^{-3}$ & $10^{-3}$ & $10^{-3}$ & $10^{-3}$ & $8 \times 10^{-3}$ & $6 \times 10^{-5}$ \\
\hline H.T. & 74.29 & 135 & 4.4 & $10^{-4}$ & $10^{-4}$ & $10^{-3}$ & $10^{-4}$ & $8 \times 10^{-3}$ & $6 \times 10^{-5}$ \\
\hline R.P. & 62.73 & 145 & 4.6 & $10^{-5}$ & & & $10^{-4}$ & $8 \times 10^{-4}$ & $6 \times 10^{-6}$ \\
\hline G.T. & 53.28 & 138 & 4.4 & $10^{-5}$ & & & $10^{-5}$ & $8 \times 10^{-5}$ & $6 \times 10^{-6}$ \\
\hline S.S. & 47.46 & 140 & 4.1 & $10^{-5}$ & $10^{-5}$ & $10^{-5}$ & $10^{-5}$ & $8 \times 10^{-4}$ & $6 \times 10^{-6}$ \\
\hline R.E. & 49.67 & 139 & 4.0 & $10^{-5}$ & $10^{-5}$ & $10^{-5}$ & $10^{-5}$ & $8 \times 10^{-5}$ & $6 \times 10^{-6}$ \\
\hline P.K. & 51.65 & 141 & 2.5 & $10^{-4}$ & $10^{-4}$ & $10^{-4}$ & $10^{-4}$ & $8 \times 10^{-5}$ & $6 \times 10^{-5}$ \\
\hline \multicolumn{10}{|c|}{ B. Panhypopituitarism } \\
\hline S.P. & 32.50 & & & $10^{-4}$ & $10^{-4}$ & $10^{-4}$ & $10^{-4}$ & $8 \times 10^{-4}$ & $6 \times 10^{-6}$ \\
\hline J.M. & 73.19 & 144 & 4.4 & $10^{-3}$ & $10^{-2}$ & $10^{-2}$ & $10^{-3}$ & $8 \times 10^{-3}$ & $6 \times 10^{-3}$ \\
\hline Median & & & & $10^{-4}$ & $10^{-4}$ & $10^{-4}$ & $10^{-4}$ & $8 \times 10^{-4}$ & $6 \times 10^{-5}$ \\
\hline Range & & & & $10^{-3}-10^{-5}$ & $10^{-2}-10^{-5}$ & $10^{-2}-10^{-5}$ & $10^{-3}-10^{-5}$ & $10^{-3}-10^{-5}$ & $10^{-3-10^{-6}}$ \\
\hline
\end{tabular}

nisolone alone, $20 \mathrm{mg}$ per day, is presented in Table IV. More than half of the patients could not detect solutions of $\mathrm{NaCl}, \mathrm{KCl}, \mathrm{NaHCO}_{3}$, or $\mathrm{HCl}$ as concentrated as 300 mmoles per $\mathrm{L}$ as different from water. For sucrose and urea, the median of the detection thresholds for the patients was 300 mmoles per L. For pyridine, thiophene, and nitrobenzene, the range of response was similar to that observed for normal subjects (Table V). Thus all values for median detection threshold are virtually the same as those observed in normal subjects. Similar results were obtained after the patients had been treated with maintenance doses of carbohydrate-active steroid and of Na-retaining steroids, with the treatment regimen described earlier.

Detection thresholds determined in J.M. at a time when he was treated with prednisolone, 2.5 mg per day, were similar to those obtained during treatment with the higher dose of prednisolone or

TABLE IV

Detection thresholds for olfaction in adrenal insufficiency treated with prednisolone

\begin{tabular}{|c|c|c|c|c|c|c|c|c|c|c|}
\hline \multirow[b]{2}{*}{ Patient } & \multirow[b]{2}{*}{ Weight } & \multirow{2}{*}{\multicolumn{2}{|c|}{$\begin{array}{c}\text { Serum } \\
\mathrm{Na}\end{array}$}} & \multirow{2}{*}{$\begin{array}{c}\text { Serum } \\
\mathbf{K}\end{array}$} & \multicolumn{6}{|c|}{ Detection threshold } \\
\hline & & & & & $\mathrm{NaCl}$ & $\mathrm{KCl}$ & $\mathrm{NaHCO}_{3}$ & Sucrose & Urea & $\mathrm{HCl}$ \\
\hline & \multicolumn{2}{|l|}{$k g$} & \multicolumn{2}{|c|}{$m E q / L$} & \multicolumn{6}{|c|}{ mmoles $/ L$} \\
\hline $\begin{array}{l}\text { A. Addison's } \\
\text { G.B. } \\
\text { J.D. } \\
\text { H.T. } \\
\text { R.P. } \\
\text { G.T. } \\
\text { S.S. } \\
\text { R.H. } \\
\text { R.E. } \\
\text { P.K. }\end{array}$ & $\begin{array}{c}\text { disease } \\
42.16 \\
68.59 \\
74.54 \\
61.27 \\
51.88 \\
46.09 \\
63.03 \\
46.75 \\
47.60\end{array}$ & $\begin{array}{l}135 \\
139 \\
138 \\
139 \\
137 \\
137 \\
132 \\
135 \\
142\end{array}$ & & & $\begin{array}{r}>300 \\
>300 \\
150 \\
>300 \\
>300 \\
150 \\
>300 \\
>300 \\
>300\end{array}$ & $\begin{array}{r}>300 \\
>300 \\
300 \\
>300 \\
>300 \\
>300 \\
>300\end{array}$ & $\begin{array}{r}>300 \\
>300 \\
150 \\
>300 \\
\\
>300 \\
>300 \\
>300\end{array}$ & $\begin{array}{r}150 \\
>300 \\
150 \\
150 \\
300 \\
300 \\
>300 \\
>300 \\
>300\end{array}$ & $\begin{array}{r}>300 \\
>300 \\
150 \\
300 \\
300 \\
300 \\
>300 \\
>300 \\
>300\end{array}$ & $\begin{array}{r}>300 \\
>300 \\
300 \\
>300 \\
>300 \\
300 \\
>300 \\
>300 \\
>300\end{array}$ \\
\hline $\begin{array}{l}\text { B. Panhypo } \\
\text { S.P. } \\
\text { J.M. } \\
\text { S.P.* } \\
\text { J.M.* } \\
\text { J.M. } \dagger\end{array}$ & $\begin{array}{l}\text { ituitarism } \\
31.50 \\
73.87\end{array}$ & $\begin{array}{l}134 \\
145\end{array}$ & & ' & $\begin{array}{r}60 \\
>300 \\
60 \\
300 \\
300\end{array}$ & & & $\begin{array}{r}60 \\
150\end{array}$ & $\begin{array}{r}120 \\
>300\end{array}$ & $\begin{array}{r}60 \\
>300\end{array}$ \\
\hline Median & & & & & $>300$ & $>300$ & $>300$ & $>300$ & $>300$ & $>300$ \\
\hline Range & & & & & $60->300$ & $300->300$ & $150->300$ & $60->300$ & $120->300$ & $60->300$ \\
\hline
\end{tabular}

* These observations were obtained during treatment with ACTH, $2.5 \mathrm{mg}$ per day.

$\dagger$ These observations were obtained during treatment with prednisolone, $5 \mathrm{mg}$ per day. 
TABLE V

Detection thresholds for olfaction of odorous vapors in four patients with adrenal insufficiency

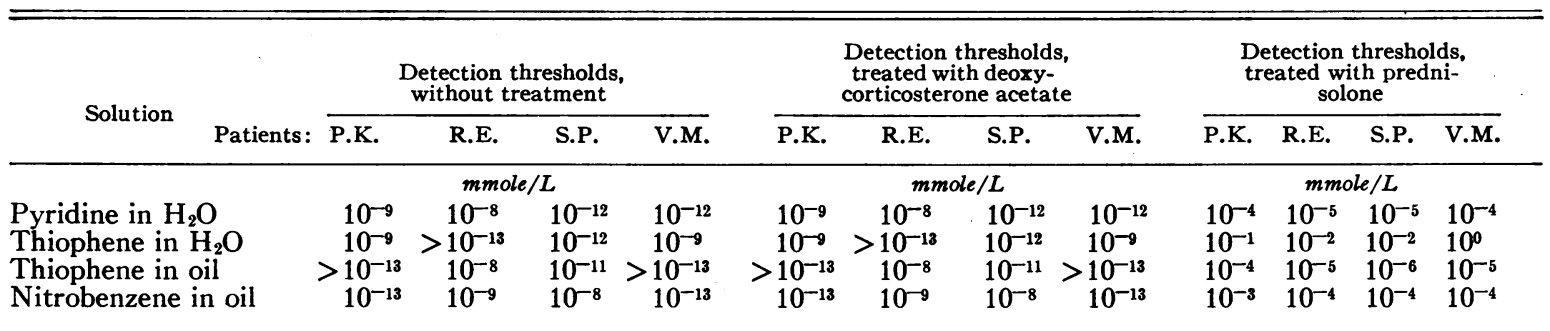

with his maintenance dose of prednisolone (5.0 $\mathrm{mg}$ per day). This lower dose of $\Delta^{1}-\mathrm{F}$ ( $2.5 \mathrm{mg}$ per day) given for 2 days changed the markedly lowered olfactory threshold values to normal, although taste thresholds for these same substances remained markedly below normal (1). Only when his maintenance dose of $5.0 \mathrm{mg}$ of $\Delta^{1}-\mathrm{F}$ was given did his taste sensitivity return to normal. Treatment with ACTH, which returned adrenal function to the normal range, returned olfactory thresholds to normal in both patients with panhypopituitarism (S.P., J.M.). It is clear that treatment with carbohydrate-active steroid returned olfactory threshold to normal in all the

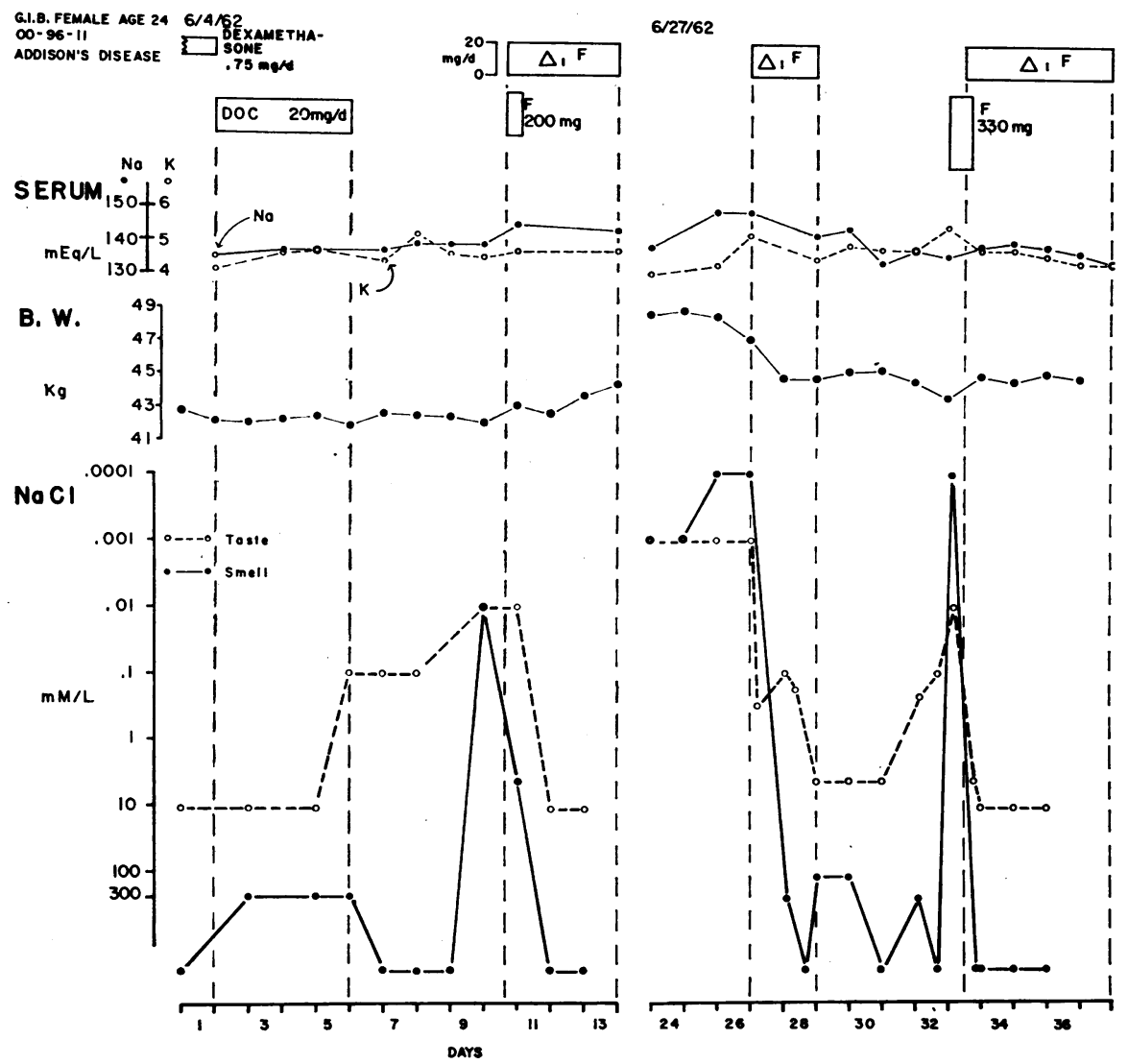

Fig. 2. THE EFFECT OF PREDNISOLONE ( $\left.\Delta^{1}-F\right)$, hydRocortisone (F), AND DEOXYCORTICOSTERONe ACETATE (DOC) ON SERUM NA AND K CONCENTRATIONS, BODY WEIGHT, AND TASTE AND OLFACTORY THRESHOLDS FOR NACL. Threshold values for taste for $\mathrm{NaCl}$ ranging from 6 to 60 mmoles per $\mathrm{L}$ and for olfaction up to $150 \mathrm{mmoles}$ per $\mathrm{L}$ are considered within the normal range of response. 
patients with adrenal insufficiency, and that it did so on a lower dosage of hormone than is necessary to return taste sensitivity to normal.

The time required for changes in smell thresholds after treatment with carbohydrate-active steroids is started or stopped is different from that for taste thresholds. This pattern, shown for $\mathrm{NaCl}$ in one patient, is characteristic for all the patients and for all the substances tested (Figure 2). On day 6, 4 days after treatment with carbohydrate-active steroids was stopped, taste sensitivity increased to the abnormal range. However, it took until day 9, 3 days after the decrease in taste threshold, for the smell sensitivity to increase to the abnormal range. On day 12,12 hours after treatment with prednisolone was begun, the smell threshold had risen to normal. An additional 12 hours was required for taste threshold to rise to the normal range. This phenomenon has been previously shown for patient J.M. Generally, the appearance of the enhanced taste sensitivity after treatment with carbohydrate-active steroids is stopped precedes that of enhanced smell sensitivity by 1 to 3 days. The return of the smell threshold to normal after treatment with carbohydrate-active steroid usually precedes that of taste threshold by 6 to 12 hours. These time relationships are at least partly dependent upon the dosage of steroid.

\section{Discussion}

Determination of olfactory detection thresholds for a variety of substances, usually considered nonodorous, that represent the basic modalities of taste (salt, sweet, bitter, and sour) and for a variety of odorous substances showed that the thresholds for all these substances were lowered in patients with untreated adrenal insufficiency and indicated that olfaction is markedly altered in this disorder. The absolute thresholds were approximately the same for all substances tested within each category (nonodorous or odorous), although thresholds for odorous substances are significantly lower than those for substances considered nonodorous. The magnitude of the difference between values for the normal state and those for adrenal cortical insufficiency was roughly the same for all substances, nonodorous or odorous. This difference is about 100,000 -fold $\left(10^{5}\right)$, with a range of $10^{3}$ to $10^{8}$. Olfactory recognition thresholds for odorous substances were also measured in the patients, but they could not be accurately determined due to the extreme variability of the patients' responses.

The thresholds observed for odorous substances in normal subjects in the present study are within the range of values of those reported in the literature, which have been obtained by various methods, some differing from the one used here (5-8). However, olfactory thresholds for substances considered nonodorous have not been previously investigated. It is clear from the results presented above that only about one-fourth of normal subjects could distinguish between water and solutions of various salts, sucrose, urea, or $\mathrm{HCl}$, and then only at high concentrations.

Since some of these substances are considered nonvolatile as well as nonodorous, it is surprising that normal subjects are able to detect them through olfaction alone. The ability of patients with untreated adrenal insufficiency to detect extremely small quantities of these substances in water is even more surprising. However, experiments in our laboratory have shown that for $\mathrm{NaCl}, \mathrm{KCl}$, and $\mathrm{HCl}$, normal subjects and patients with untreated adrenal insufficiency are in reality responding to the vapor of chlorine gas, released in minute amounts, presumably by the action of light energy on the chloride ions in solution (9). Some normal subjects can detect this vapor easily in concentrated solutions of $\mathrm{NaCl}, \mathrm{KCl}$, and $\mathrm{HCl}$. Patients with untreated adrenal cortical insufficiency can detect it with ease, even in very dilute concentrations.

The mechanism by which normal subjects and patients with adrenal cortical insufficiency detect $\mathrm{NaHCO}_{3}$, sucrose, and urea from water is not as clear. It appears likely that around the narrow necks of the bottles containing all of these solutions there are microatmospheres of the solutes in solution. The solution may be determined from many factors, e.g., the vapor pressure of the solute or the altered vapor pressure of the solvent. Even though the concentration of solute in vapor phase must be very small, approximately one-fourth of normal subjects can make these detections in solutions at high concentrations, and all patients with adrenal cortical insufficiency tested off treatment 
could easily make these detections, even at very low concentrations. Whether the detection of $\mathrm{Na}$ $\mathrm{HCO}_{3}$, sucrose, or urea indicates detection of these specific solutes or detection of microconcentrations of impurities, which might be more volatile, in these solutions is not known. Furthermore, it is not known what role aerosols or charged particles might play in producing these detections by causing depolarization of the olfactory epithelium-olfactory nerve, with the subsequent production of an action potential. However, it is clear that detection without recognition does take place consistently and that this detection can be made more sensitive if carbohydrate-active steroids alone are withdrawn from the treatment of a patient with adrenal cortical insufficiency.

Treatment with carbohydrate-active steroid returned the taste threshold for all test substances to normal in all patients with adrenal cortical insufficiency. This change occurred usually within 1 day after treatment was initiated. This is in contrast to the much longer time ( 5 to 7 days) required for the reappearance of increased sensitivity after steroid therapy had been discontinued. Treatment with DOC alone for as long as 7 days did not alter the abnormal taste threshold (Figure 2). Normal subjects treated for as long as 5 days with large doses of $\Delta^{1}-\mathrm{F}$ (20 mg per day) showed no change in olfactory threshold (10).

The time patterns of sensitivity change suggest that the olfactory sense may be less sensitive to the absence of carbohydrate-active steroid than is the gustatory sense. This is suggested by the fact that a longer period of time off treatment with carbohydrate-active steroids is required to produce increased smell sensitivity when compared with taste sensitivity. However, once the olfactory system is "activated" it appears capable of making detections with significantly greater sensitivity than that of the gustatory system. The median detection thresholds for smell are 10 to 100 times more sensitive than those for taste for each of the substances tested for both smell and taste in patients with adrenal cortical insufficiency. These results allow the speculation that carbohydrate-active steroids, which are normally present in the nervous system $(11,12)$, act normally as inhibitory substances in the nervous system. When the concentration of carbohydrate-active steroids in the nervous system decreases significantly, as occurs after adrenalectomy (11), sensory sensitivity increases, i.e., the normal inhibitory action of these hormones may be removed and stimuli that normally would not elicit a response do so. When these hormones are replaced, normal inhibition reoccurs and sensitivity returns to normal.

The relationship of serum electrolyte concentrations and body weight to taste and smell thresholds during treatment with carbohydrate-active steroid and DOC is shown for one patient in Figure 2. Only prednisolone returned olfactory thresholds to normal while hyponatremia and hyperkalemia were still present. DOC did not affect taste or smell thresholds, but it returned serum sodium and potassium concentrations to normal and produced a marked gain in body weight. This pattern of response was similar for all substances tested in all the patients with adrenal insufficiency (Tables II-IV). In normal subjects made hyponatremic by treatment with Pitressin and water, olfactory thresholds remained unchanged, even with concentrations of serum sodium as low as $112 \mathrm{mEq}$ per L.

In a number of non-Addisonian subjects deprived of sodium or treated with DOC (10), olfactory thresholds remained unchanged. A number of patients studied in this series who had developed severe hyponatremia and contraction of extracellular volumes as a result of a variety of disease states showed no abnormality in taste or olfactory thresholds. Similarly, in a large number of patients with a variety of acute and chronic debilitating illnesses not involving disease of the adrenal cortex, no significant alteration in olfaction could be found (10). On the other hand, an increased olfactory sensitivity has been found in patients without alterations in total body water or sodium. In patients with cystic fibrosis, despite normal concentrations of sodium and potassium in the serum, olfactory thresholds are as low as those observed in patients with adrenal insufficiency (3)..$^{2}$ Despite treatment with DOC or predniso-

2 Preliminary observations suggest that the increased olfactory sensitivity in patients with cystic fibrosis is a genetic characteristic of some of these children (10). Other observations suggest that a few "normal" subjects, including a family of both parents and two siblings with normal adrenal function, can exhibit persistently decreased taste and smell thresholds (10). 
lone, with accompanying changes in water and electrolyte metabolism, these thresholds remain unchanged. These observations suggest that the olfactory sensitivity is independent of the concentration of sodium or potassium in the serum and of changes in extracellular fluid volume.

The ability to restore olfactory threshold to normal is not limited to a single carbohydrate-active steroid. Furthermore, excessive amounts of steroid need not be given to restore olfaction to normal. At the time of admission, the patients with adrenal insufficiency had been taking only cortisone acetate, $37.5 \mathrm{mg}$ per day, or prednisolone, $5 \mathrm{mg}$ per day, or dexamethasone, $0.5 \mathrm{mg}$ per day, or dexamethasone, $0.5 \mathrm{mg}$ per day with $9-\alpha$-fluorohydrocortisone, $0.05 \mathrm{mg}$ or $0.1 \mathrm{mg}$ per day. At this time, all olfactory thresholds were in the normal range, and they were comparable to those obtained during treatment at a dosage of prednisolone (20 mg per day) much greater than the usual dose for these patients.

When the dosage is adequate, however, the amount of carbohydrate-active steroid does appear to influence the rate of return of olfactory thresholds to normal. Whereas effective doses of prednisolone corrected the abnormal olfactory response within 12 to 18 hours in all patients, a massive dose of hydrocortisone $(330 \mathrm{mg}$ ) given intravenously to a patient over a 6-hour period corrected the abnormal olfactory response within that period. A smaller, but nonetheless "pharmacological," dose of hydrocortisone (200 mg) given intravenously to this same patient over an 8-hour period was not effective until 12 hours had elapsed.

It is commonly held that the sense of smell complements the sense of taste: In these studies an increase in taste sensitivity was observed upon suspension of treatment before the increase in smell sensitivity, and it did not change when smell sensitivity changed. Thus, increased taste sensitivity does not appear dependent upon an increased smell sensitivity.

The mechanism by which carbohydrate-active steroids alter olfactory threshold is not clear. Anatomically, the taste pathway is initiated at the taste bud and mainly follows the tracts of the seventh and ninth cranial nerves to termini in the thalamus. The olfactory pathway is initiated in the olfactory epithelium and proceeds via the olfactory nerves through the olfactory bulb to termini in the pyriform area and hippocampus. The receptor sites, tracts, and brain areas are thus distinctly separated anatomically, yet they both respond in similar fashion to the steroid lack. Where, anatomically, the effects occur is not known; neither are the biochemical changes underlying them. The effects illustrated in those experiments relate only to the sensory aspects of nervous system function. However, the role of adrenocorticosteroids in the nervous system as a whole is undoubtedly an important one, perhaps related in some fundamental way to the manner in which the sensory system operates.

\section{Summary}

Olfactory thresholds for $\mathrm{NaCl}, \mathrm{KCl}, \mathrm{NaHCO}_{3}$, sucrose, and urea were determined in 11 patients with adrenal cortical insufficiency ( 9 with Addison's disease and 2 with panhypopituitarism) and compared to those in normal volunteers. Olfactory thresholds for pyridine, thiophene, and nitrobenzene were also determined in four patients with adrenal cortical insufficiency. In adrenal insufficiency the olfactory sensitivity was roughly 100,000 times (range $10^{3}$ to $10^{8}$ ) more acute than that in the normal subjects.

Treatment of the patients with deoxycorticosterone acetate, $20 \mathrm{mg}$ per day, returned serum sodium and potassium concentrations to normal and produced gains in body weight, but did not alter olfactory threshold. Olfactory threshold for all modalities was unchanged in a variety of conditions in which alterations in the concentration of serum sodium were produced or occurred naturally.

Treatment with prednisolone, $20 \mathrm{mg}$ per day, returned olfactory thresholds to normal in every patient within the first day, frequently before any change in serum electrolyte concentrations or body weight. When treatment with prednisolone was stopped, the increased olfactory sensitivity did not reappear for 5 to 7 days, or 1 to 3 days after taste sensitivity had become maximal.

The nature of the effect of carbohydrate-active steroids on olfaction is not known. It may be related to a generalized effect on nervous system function, particularly the sensory system. 


\section{References}

1. Henkin, R. I., J. R. Gill, Jr., and F. C. Bartter. Studies on taste thresholds in normal man and in patients with adrenal cortical insufficiency: the role of adrenal cortical steroids and of serum sodium concentration. J. clin. Invest. 1963, 42, 727.

2. Henkin, R. I., and D. H. Solomon. Salt-taste threshold in adrenal insufficiency in man. J. clin. Endocr. 1962, 22, 856.

3. Henkin, R. I., and G. F. Powell. Increased sensitivity of taste and smell in cystic fibrosis. Science 1962, 138, 1107.

4. Wright, R. H. Personal communication.

5. Allison, V. C., and S. H. Katz. An investigation of stenches and odors for industrial purposes. J. indust. engin. Chem. 1919, 11, 336.

6. Crocker, E. C., and L. B. Sjostrom. Odor detection and thresholds. Chem. engin. News 1949, 27, 1922.
7. Jones, F. N. Olfactory absolute thresholds and their implications for the nature of the receptor process. J. Psychol. 1955, 40, 223.

8. Baker, R. A. Threshold odors of organic chemicals. J. Amer. Water Works Ass. 1963, 55, 913.

9. Henkin, R. I., and H. C. Fales. On the mechanism of the olfactory perception of the vapor of sodium chloride. In preparation.

10. Henkin, R. I. Unpublished observations.

11. Henkin, R. I., and F. C. Bartter. The presence of corticosterone and cortisol in the central and peripheral nervous system of the cat. Program of the 48th Meeting of the Endocrine Society, June 20-22, 1966, p. 37.

12. Touchstone, J. C., M. Kasparow, P. A. Hughes, and M. R. Horwitz. Corticosteroids in human brain. Steroids 1966, 7, 205. 